\title{
A ESTRUTURA DE CAPITAL E A PERFORMANCE DAS FIRMAS: uma análise empírica em companhias abertas no Brasil
}

\author{
Capital structure and firm performance: an empirical \\ analysis of listed firms in Brazil
}

\footnotetext{
Cleci Grzebieluckas ${ }^{a}$, Rosilene Marcon ${ }^{\mathrm{b}}$, Anete Alberton ${ }^{\mathrm{c}}$, Rodrigo Bandeira-de-Mello ${ }^{\mathrm{d}}$

${ }^{a}$ Doutoranda da Universidade Federal de Santa Catarina, UFSC, Florianópolis, SC - Brasil, e-mail: cleci@unemat.br

${ }^{b}$ Economista, Dr. ${ }^{a}$ Prof. ${ }^{a}$ da Universidade do Vale do Itajaí, Programa de Pós-Graduação em Administração e Turismo, UNIVALI, Florianópolis, SC - Brasil, e-mail: rmarcon@univali.br

${ }^{c}$ Engenheira Civil e Administradora, Dr. ${ }^{a}$, Prof. ${ }^{a}$ da Universidade do Itajaí, Programa de Pós-Graduação em Administração e Turismo, UNIVALI, Florianópolis, SC - Brasil, e-mail: anete@univali.br

d Engenheiro Civil, Dr. Prof. da Universidade do Itajaí, Programa de Pós-Graduação em Administração e Turismo, UNIVALI, Florianópolis, SC - Brasil, e-mail: rmello@univali.br
}

\begin{abstract}
Resumo
O presente estudo teve como objetivo verificar empiricamente a influência da estrutura de capital na performance das Companhias Abertas no Brasil. A análise de regressão múltipla foi utilizada a fim de avaliar tal influência. Compuseram a amostra um total de 130 empresas de capital aberto, atuando em 16 setores da economia brasileira, no período de 1999 a 2005. As variáveis de performance utilizadas foram: rentabilidade do ativo (ROA), rentabilidade operacional do ativo (ROAOP) e rentabilidade do patrimônio líquido (ROE). Três modelos de regressão foram utilizados. O primeiro analisou a influência do endividamento de curto prazo na performance, o segundo, o endividamento de longo prazo, e o terceiro, o endividamento geral. Para os três modelos foram utilizadas duas variáveis de controle, o crescimento das vendas e o tamanho da empresa que foi medido pelo $\log$ das vendas. Os resultados sugerem uma significativa relação negativa entre o endividamento de curto prazo nas variáveis ROA e ROE. Já para os setores, somente alguns deles tiveram significância estatística, geralmente, no endividamento de curto prazo.
\end{abstract}

Palavras-chave: Estrutura de capital; Endividamento; Performance. 


\begin{abstract}
The aim of this research was to verify the influence of capital structure on performance of Brazilian companies. We performed a multiple cross section study of the 1999 to 2005 period range. The sample sourcing came from Economatica and the main variables examined were the debt equity Ratio (ENDV), the return on assets (ROA), the operational return on assets (ROAOP) and the return on equity (ROE). The results showed a significantly negative relation between the ratio of short-term debt to ROA, ROAOP and ROE. With regard the others debt ratios, the results showed a negative relation, but not significantly.
\end{abstract}

Keywords: Capital structure; Leverage; Performance.

\section{INTRODUÇÃO}

Desde o trabalho seminal de Modigliani e Miller (1958), o assunto estrutura de capital representa uma incógnita e continua foco de debates, tanto no meio acadêmico como empresarial. Há uma extensa literatura fornecendo evidências teóricas e empíricas para identificar características determinantes associadas as firmas e sua estrutura de capital, todavia, somente uma pequena fração das variações é explicada. Dentre os principais estudos, estão os de Modigliani e Miller (1958, 1963), Baxter (1967), Jensen e Meckling (1976), Ross (1977), DeAngelo e Masulis (1980), Myers (1984), Myers e Majluf (1984), Narayanan (1988), Baskin (1989) Heinkel e Zechner (1990) e os de Rajan e Zingales (1995).

No Brasil, diversos estudos teóricoempíricos têm sido realizados com o objetivo de elucidar o assunto, tais como os de Eid Jr. (1996), Kayo e Famá (1997), Famá, Barros e Silveira (2001), Perobeli e Famá (2003), Nakamura, Martin e Kimura (2004), Procianoy e Schnorrenberger (2004), Prates e Leal (2005), dentre outros que avaliaram os determinantes de influência nas decisões do endividamento, porém, usando as variáveis de endividamento sendo explicadas pelo desempenho. Por outro lado, trabalhos nacionais como os de Famá e Melher (1999), Pereira (2000), Mesquita e Lara (2003) e Abras et al. (2003), analisaram a influência da estrutura de capital no desempenho das empresas.

O estudo da estrutura também tem sido foco da área da estratégia como em Barton e Gordon (1988), Balakrishnan e Fox (1993) e Kochhar (1997). Estes trabalhos têm buscado analisar a relação entre a estrutura de capital e fatores relacionados à habilidade da firmas em competir.

Simerly e Li (2000) advogam que a estrutura de capital ao longo do tempo tem sido um importante assunto do ponto de vista da economia financeira, pois está ligada às habilidades da firma em atender as demandas de vários stakeholders. Bandeira-de-Mello e Marcon (2004) defendem que em países emergentes como o Brasil, em que as variáveis macro econômicas estão fundamentadas na política monetária, e com o constante controle da inflação, é fundamental utilizar indicadores em que o efeito dessas políticas possam ser melhor identificados. Tais efeitos exercem influência de formas variadas sobre a performance, destacando-se, por um lado, a elevação do custo do financiamento, tanto interno quanto externo, dadas as altas taxas de juros e a desvalorização cambial, impactando diretamente no desempenho das empresas.

Diante do cenário apresentado, o estudo tem como objetivo analisar a influência da estrutura de capital na performance das empresas brasileiras no período de 1999-2005, visto que este tema é ainda pouco explorado e carente de estudos na literatura brasileira de finanças.

Nas seções seguintes serão apresentados a revisão teórica, os aspectos metodológicos, a análise dos resultados e as considerações finais.

\section{REFERENCIAL TEÓRICO}

A partir da argumentação de Modigliani e Miller (1958) sobre a irrelevância da estrutura de capital, surgiram diversos trabalhos abordando 
temas relacionados aos financiamentos das empresas. No princípio, as pesquisas eram predominantemente sobre a estrutura ótima de capital, abordando basicamente alguns pontos principais: os custos de agência (JENSEN; MECKLING, 1976), sinalização dos efeitos da qualidade da firma (ROSS, 1977), a pecking order theory ao considerar que as empresas obedecem uma hierarquia para financiar novos projeto (MYERS, 1984) e a assimetria de informações (MYERS; MAJLUF, 1984).

Modigliani e Miller (1958) argumentaram que o valor da firma é independente de sua estrutura de capital partindo do princípio de que haveriam mercados de capital perfeitos, isto é, não haveriam impostos, custo de transação e custos de falência. Uma outra condição foi a informação simétrica como, por exemplo, investidores e administradores têm igual informação sobre o potencial de investimentos da firma. O estudo de Modigliani e Miller (1958) tomou como base mercados de capitais perfeito tais como, a inexistência de impostos e a total condição de se tomar dinheiro emprestado à taxa livre de riscos. Em seu segundo artigo, Modigliani e Miller (1963) moderaram a suposição da inexistência de impostos, considerando que as empresas estavam sujeitas a pagar imposto de renda sobre seus lucros. A partir dessa mudança e devido a possibilidade das empresas poderem deduzir seus juros para fins de imposto de renda, concluía-se que estas deveriam trabalhar com um potencial elevado de dívida.

Jensen e Meckling (1976) inseriram o custo de agência observando os conflitos de interesse inerentes a divisão da firma em obrigações e direitos assimétricos entre acionistas, gerentes e credores, uma vez que a bifurcação assimétrica da firma cria oportunidade de aumento de valor de um grupo à custa de outro. Muitas vezes, com a redução do valor do negócio, utiliza-se a estrutura de capital para minimizar tais conflitos. "O endividamento contribui para que o gerente se empenhe em maximizar o valor da empresa, na medida em que aumenta sua participação relativa na mesma e em seus lucros, além de reduzir os fluxos de caixa livres passíveis de destinação nãoprodutiva" (BRITO; LIMA, 2005, p. 8).

Ross (1977) postulou que a estrutura de capital sinalizaria ao mercado a verdadeira situação financeira da empresa. Os investidores tomariam como sinal de qualidade o nível de endividamento das empresas de modo que empresas de menor rentabilidade procurariam baixos níveis de endividamento. Aquelas com menor risco e maior qualidade tenderiam a níveis maiores de endividamento.

Myers (1984) em seu artigo intitulado 'O quebra-cabeça da estrutura de capital', divide seu trabalho em duas correntes de pensamento sobre a estrutura de capital. A primeira, denominada de static trade off, a qual utiliza um modelo em que busca balancear o risco de falência das altas cargas de dívidas e os benefícios fiscais do endividamento. Desde então a perspectiva do trade off sugere uma relação proporcional entre a alavancagem financeira e a performance econômica (ANDERSEN, 2005). A segunda corrente, que Myers denominou de pecking order theory, defende que os administradores da empresa estabelecem uma ordem de preferência para financiar seus projetos internos, primeiramente, fontes de financiamentos internos, segundo, por meio de novas dívidas e, por último, a captação de recursos através da emissão de ações.

Myers e Majluf (1984) analisaram, ainda, os efeitos da assimetria de informações dos quais os gerentes internos detém mais conhecimentos sobre as oportunidades de investimentos do que os credores e financiadores externos. Nesta conjuntura, a estrutura de capital pode ser determinada pelo pecking order theory, com o qual a empresa prefere usar fontes internas para financiar bons projetos e somente assume investimentos externos quando há a necessidade de fundos ou projetos adicionais menos atrativos. Neste caso, a relação entre alavancagem e performance econômica é mais indeterminada (ANDERSEN, 2005).

Já na década de 80, alguns trabalhos começaram a surgir, como os de Barton e Gordon (1988), Skely e Collins (1988), Balakrishnan e Fox (1993), Simerly e Li (2000) e Andersen (2005), objetivando verificar outros fatores associados à estrutura ótima de capital, tais como: a cultura, o ambiente, a performance, as estratégias corporativas e a heterogeneidade das firmas.

Estudos como o de Balakrishnan e Fox (1993) ao pesquisarem a heterogeneidade da firma e a estrutura de capital de 295 empresas operando no setor de mineração e fabricação, examinaram a relação entre as características da firma e 
indústria. Suas descobertas foram que os fatores específicos da firma como pesquisa e desenvolvimento, adversidades, depreciação, oportunidades de crescimento e risco apontaram $52 \%$ da variância na estrutura de capital.

O resultado encontrado por Balakrishnan e Fox (1993) reforça o que Barton e Gordon (1988) evidenciaram ao analisar estratégia corporativa e a estrutura de capital. O conceito estratégia pode ser incorporado ao tradicional efeito financeiro dentro da reconhecida e complexa natureza idiossincrática do comportamento gerencial de uma firma individual. Desta forma, os resultados de Barton e Gordon (1988) sugerem que uma escolha gerencial pode ajudar a explicar a preferência da estrutura de capital.

Ao pesquisar a influência cultural na estrutura de capital de 677 firmas, 9 setores em 23 países, Skely e Collins (1988) concluíram que diferenças culturais contribuem significativamente na estrutura de capital. O estudo também encontrou pequeno impacto da indústria nos índices de débitos que, na visão dos autores, contradiz alguns trabalhos anteriores.

Ao analisar a estrutura de capital e performance em ambientes turbulentos, Simerly e Li (2000) observaram que turbulência e estrutura de capital estão associadas a performance e que, em ambientes estáveis, uma grande alavancagem tem impacto positivo na performance das firmas e impacto negativo em ambientes dinâmicos.

Andersen (2005) analisou o risco gerencial de 1357 empresas americanas operando em diversos setores da economia. $\mathrm{O}$ autor verificou que o risco gerencial tem uma relação positiva na performance econômica e geralmente é associada com alta alavancagem financeira. Em resumo, para melhorar os efeitos da performance econômica do efetivo risco gerencial, a alavancagem financeira não deveria ser excessiva (ANDERSEN, 2005).

No Brasil, diversos estudos empíricos abordaram a teoria da estrutura de capital. Eid Jr. (1996) ao pesquisar o comportamento das empresas brasileiras dos mais variados setores e tamanhos, no tocante ao custo e estrutura de capital, destacou que empresas brasileiras agem oportunisticamente, ou seja, captam os recursos que no momento forem economicamente mais vantajosos sem se preocupar com a estrutura de capital. Medeiros e Daher (2004) confirmam a pecking order theory para empresas brasileiras, mas de forma fraca, pois os modelos mostram que os volumes de emissões de ações são menores do que os das outras formas de funding.

Trabalho idêntico e com resultados semelhantes aos de Eid Jr., porém em categorias diferentes de empresas, foi encontrado por Oliveira e Antonialli (2004). Os autores pesquisaram 69 empresas do ramo agroindustrial de diversos tamanhos e tipos de constituição jurídica do Estado de Minas Gerais. A pesquisa concluiu que 45,6\% das empresas estudadas preferem mudar sua estrutura de capital quando surge uma nova oportunidade de investimento, sendo que 43,3\% dessas empresas utilizam 100\% de recursos próprios sob alegação de que o custo do capital próprio não é tão oneroso quanto o de terceiros.

Prates e Leal (2005) tomaram como fonte os gerentes financeiros, diretores e presidentes de 30 empresas brasileiras de diferentes características. Os resultados sugerem que as práticas de endividamento não parecem ser ditadas pelo nível de alavancagem, pela capacidade de pagamento, pelo tamanho ou tipo de sociedade das empresas, mas pela observação da redução do custo de capital, dos custos de transação sobre o endividamento e da percepção de risco pelo mercado confirmando, assim, a teoria do trade off. $\mathrm{O}$ resultado da pesquisa corroborou com o market timing (janela de oportunidades), tendo em vista que empresas apontaram estar sempre atentas ao menor custo para financiar suas oportunidades de crescimento.

Prates e Leal (2005) relataram não identificar uma teoria predominante que explique o comportamento das empresas. Os resultados parecem concordar com o estudo anterior de Bancel e Mittoo (2004) que pesquisaram gerentes financeiros de 16 países europeus no tocante a estrutura de capital, os quais identificaram que as políticas de financiamento das firmas são influenciadas pelo ambiente institucional e suas operações internacionais. A pesquisa também revelou que as firmas determinam sua estrutura por meio do trade off e, em caso de alteração na estrutura do capital, levam em consideração as janelas de oportunidades.

Kayo e Famá (1997) pesquisaram 281 empresas brasileiras de capital aberto, objetivando verificar se os efeitos positivos ou negativos do endividamento podem influenciar a formação da 
estrutura de capital. Os autores concluíram que quando existem boas oportunidades de crescimento as empresas tendem a se endividar menos do que as com poucas oportunidades de crescimento. Empresas menos rentáveis apresentaram percentual de $27 \%$ de endividamento maior em relação as mais rentáveis, onde a média de débitos das primeiras era de $23,34 \%$ do endividamento financeiro, as mais rentáveis apresentaram $18,34 \%$ de débitos financeiros em relação aos ativos contábeis.

Jorge e Armada (2001) ao analisar os fatores determinantes do endividamento das empresas portuguesas, verificaram que as variáveis dimensão e vantagens fiscais não são resultantes do endividamento. Os autores identificaram também que o controle acionário e o setor de atividade não pareceram determinantes do endividamento. Por outro lado, as empresas portuguesas possuem um índice de $52 \%$ de endividamento geral sobre o ativo total, contra 20,72\% encontrado por Kayo e Famá (1997) para empresas brasileiras no mesmo período e 27,14\% para o G7 (Japão, França, Estados Unidos, Canadá, Itália, Alemanha e Reino Unido), verificados por Rajan e Zingales (1995).

O estudo de Pereira (2000) que teve como objetivo avaliar se ao se endividarem as empresas brasileiras geram valor aos acionistas, concluiu que existe um forte relacionamento positivo entre valor e alavancagem. A pesquisadora encontrou um índice $27,9 \%$ de endividamento geral em relação ao patrimônio líquido. Este indicador também se apresenta abaixo em relação aos países do G7 pesquisados por Rajan e Zingales (1995) que em 1991 apresentavam um endividamento médio de 40,85\%. Rajan e Zingales (1995) ainda demonstraram que os ativos tangíveis tamanho da firma e lucratividade foram significantes para explicar a estrutura de capital dos países desenvolvidos. Os ativos tangíveis podem ser usados como colaterais e, por conseguinte, associados com alta alavancagem.

Resultado semelhante ao de Rajan e Zingales (1995) no Brasil foi encontrado por Nakamura, Martin e Kimura (2004), abordando fundamentalmente indicadores contábeis de demonstrações financeiras trimestrais em empresas brasileiras no período de 1999 a 2003. Os pesquisadores constataram que rentabilidade operacional, grau de imobilização e índice valor de mercado sobre valor contábil do capital próprio são variáveis relevantes para explicar a política de endividamento. No tocante ao endividamento financeiro de longo prazo, os dados indicaram que empresas que pagam mais impostos, de maior porte, com maior grau de tangibilidade e elevado crescimento em vendas são mais endividadas de longo prazo. Estes dados confirmam as afirmações de Bastos e Hidalgo (2005) de que empresas menores enfrentam dificuldade de financiamento de longo prazo devido a não existência de colaterais como garantia.

Seguindo a mesma linha de pesquisa, Perobelli e Famá (2003) analisaram os países latinos: México, Argentina e Chile. Para as empresas desses países, os autores encontraram resultados semelhantes aos de Kayo e Famá (1997) no Brasil, isto é, empresas mais lucrativas e em crescimento são menos endividadas, corroborando, portanto, com o pecking order theory. Por outro lado, o fator tamanho corrobora com Nakamura, Martin e Kimura (2004), indicando que, quanto maior o tamanho da empresa, maior o endividamento de longo prazo.

Lucinda e Saito (2002) pesquisaram os determinantes do endividamento das empresas brasileiras e verificaram que firmas com baixo grau de assimetria de informação e com boas oportunidades de investimento lucrativo tendem a um maior endividamento junto ao mercado. $\mathrm{O}$ modelo indicou que o ajustamento em relação a um nível considerado ótimo por parte das empresas seria um elemento importante na determinação de endividamento em contraposição ao modelo de hierarquia de fontes, ou seja, o trade off se sobrepõe ao pecking order.

Com o objetivo de verificar a relação entre a estrutura de capital das empresas da América Latina, Famá e Melher (1999) identificaram que não há diferenças significativas na estrutura de capital das empresas do Brasil em relação às demais da América Latina. A dimensão capital de terceiros não apresentou relação com o resultado, seja ele positivo ou negativo. A estrutura de capital não explica o desempenho negativo das empresas no Brasil em comparação com as empresas de outros países Latinos. Como estudos anteriores já apontaram, empresas mais rentáveis tendem a ser menos endividadas do que as menos lucrativas.

A pesquisa de Famá e Melher (1999) ressalta, ainda, que as 50 empresas de maiores prejuízos na América Latina tiveram o quociente 
de endividamento em média 2,60 vezes acima das 50 empresas com maior lucro. Portanto, os autores concluíram que para empresas rentáveis, quanto mais capital de terceiros, melhor sua rentabilidade. Por outro lado, para empresas não rentáveis, quanto mais capital de terceiros, maior o prejuízo.

Abras et al. (2003) pesquisaram 58 empresas brasileiras operando em 4 setores, objetivando avaliar a alavancagem financeira, o ambiente e a performance. Os resultados obtidos apresentaram evidências estatísticas de que a turbulência do ambiente e a alavancagem impactam, de forma e graus diferentes, na performance. Dependendo do setor, tanto a alavancagem quanto o ambiente reduzem o desempenho de suas firmas.

Mesquita e Lara (2003) analisaram a estrutura de capital e a lucratividade de 70 empresas brasileiras e concluíram que os índices de retornos e débitos indicaram relação positiva com os financiamentos de curto prazo e relação negativa com financiamentos de longo prazo e patrimônio líquido, ou seja, quanto maior as dívidas de longo prazo em relação ao patrimônio líquido, menor o retorno.

Procianoy e Schnorrenberger (2004) analisaram a influência do controle acionário nas decisões de estrutura de capital das empresas brasileiras. Os autores identificaram que, quanto mais concentrada a estrutura da companhia, maior é a aversão ao risco. Também as variáveis: tamanho, lucratividade, ano e setor a que pertence à empresa, exercem influência nas decisões de estrutura de capital.

É relevante salientar que fatores que são importantes para a estrutura de capital de empresas no exterior podem não ter o mesmo poder de explicação quando replicados para as empresas brasileiras. As menores fontes de financiamento e os juros reais mais elevados, além de um nível de inflação maior que o de países desenvolvidos, são características típicas da realidade brasileira e, portanto, não considerados pelos financistas norteamericanos.

Observa-se, portanto, que não existe uma teoria universal sobre uma ótima alavancagem. Diferentes pontos de vista têm sido emitidos no que se refere às escolhas de financiamentos e, além dos aspectos que interligam a estrutura de capital largamente estudados a partir da teoria de Modigliani e Miller, outros estudos mais recentes estão focando a estratégia, o ambiente de negócios e a performance, ligados a estrutura de capital, objetivo deste trabalho.

A partir do exposto e tomando, principalmente, do referencial teórico dos estudos empíricos realizados anteriormente por Famá e Melher (1999), Pereira (2000), Simerly e Li (2000), Mesquita e Lara (2003), Abras et al. (2003) e Abor (2005) que analisaram a influência da estrutura de capital na rentabilidade das empresas, formulamse as hipóteses descritas a seguir:

H1: a performance financeira das empresas está negativamente relacionada com o endividamento de curto prazo;

H2: a performance financeira das empresas está positivamente relacionada com o endividamento de longo prazo;

Considerando, em especial, os trabalhos de Perobelli e Famá (2002), Bastos e Hidalgo (2005) identificaram que empresas menores têm mais dificuldade em contrair empréstimos de longo prazo devido a falta de colaterais como garantia e, portanto, as fontes de financiamentos de curto prazo, sem subsídios por parte do governo, acarretam altos índices nas taxas de juros. As linhas de financiamento de longo prazo como as do BNDES são incomparavelmente mais baixas do que as taxas de juros para capital de giro, praticadas pelos bancos privados (BARCELOS, 2002). Portanto, o pressuposto adotado sugere que empresas mais endividadas no curto prazo têm menor rentabilidade em relação àquelas com débito de longo prazo. Partindo desse pressuposto, uma hipótese subjacente é a de que:

H3: a performance financeira das empresas é influenciada mais negativamente pelo endividamento de curto prazo do que o de longo prazo.

\section{METODOLOGIA}

Com o objetivo de avaliar se a estrutura de capital influencia na performance das empresas brasileiras, o presente estudo utilizou os dados financeiros e contábeis de empresas de capital aberto listadas na Bovespa e publicadas na base do ECONOMÁTICA®. 
Da base foram coletados dados dos anos de 1999 a 2005, cuja escolha é justificada pela estabilidade econômica do país neste período, visto que, nos anos anteriores, a economia brasileira encontrava-se em fase de reestruturação. Foram obtidos, inicialmente, dados de 550 empresas, distribuídas em 20 setores, conforme a especificação apresentada na base (Agro e Pesca, Alimentos e Bebidas, Comércio, Construção, Eletroeletrônicos, Energia Elétrica, Finanças e Seguros, Máquinas Industriais, Mineração, Minerais Não Metálicos, Outros, Papel e Celulose, Petróleo e Gás, Química, Siderurgia e Metalurgia, Software e Dados, Telecomunicações, Têxtil, Transporte e Serviços, Veículos e peças). Desta base inicial foi excluído o setor Finanças e Seguros, devido ao alto grau de alavancagem.

Também foram excluídas as empresas que apresentaram alavancagem negativa e o endividamento sobre o patrimônio líquido superior a $250 \%$. Outra exigência foi que as empresas tivessem informações das vendas em pelo menos 4 dos 7 anos estudados. Após esses procedimentos realizou-se o tratamento dos outliers, e, apesar de Hair et al. (2005) sugerirem 2,5 desvios padrão, para o presente estudo foi utilizado três desvios padrão para mais e para menos.

Tendo em vista que algumas variáveis exibiram um desvio estatisticamente significativo da normalidade, estas foram transformadas a fim de obter distribuição normal. Por exemplo, a variável endividamento geral (ENDgl) foi utilizado o $\log 10$, enquanto que para as variáveis endividamento de curto prazo (ENDcl) e endividamento de longo prazo (EDVlp) utilizou-se raiz quadrada. Já a variável crescimento das vendas (CRESv) apresentou significância estatística, porém foi incluída na amostra por se apresentar graficamente normal.

O presente trabalho tomou como base a pesquisa de Abor (2005) que avaliou a relação entre a estrutura de capital e a rentabilidade medida pela rentabilidade do patrimônio líquido (ROE) de 22 setores do Oeste da África. Para o presente estudo foram utilizadas mais duas variáveis de performance a rentabilidade operacional do ativo (ROAOP) e a rentabilidade do ativo (ROA), as quais encontram-se descritas no Quadro 1.

Abor (2005) utilizou três modelos de regressão a fim de avaliar a influência de cada endividamento, curto prazo, longo prazo e endividamento geral sobre o patrimônio líquido. A exemplo de Abor (2005) também foram utilizadas duas variáveis de controle em todos os modelos de regressão, o crescimento das vendas (CRESv) e o tamanho da empresa (TAM) medido pelo $\log$ das vendas.

A fim de remover a multicolinearidade entre as variáveis de endividamento, tal como em Abor (2005), foram elaborados três modelos de regressão. O modelo I analisa o endividamento de curto prazo (ENDcp) juntamente com as variáveis de controle CRESv e TAM; o modelo II de endividamento de longo prazo (ENDlp) e as variáveis de controle; e o mesmo procedimento para o modelo III com a variável endividamento geral (ENDgl) e as variáveis de controle CRESv e TAM. O Quadro 1 descreve como cada variável foi mensurada.

O modelo de regressão linear múltipla utilizado para analisar a influência da estrutura de capital e variáveis de controle na performance é representado pelas equações 1, 2 e 3:

$$
\begin{aligned}
& \text { PERFORMANCE }_{i}=\beta_{o}+\beta_{1} \text { ENDcp }_{i}+\beta_{2} \text { CRESv }_{i}+\beta_{3} \text { TAM }_{i} \\
& \text { PERFORMANCE }_{i}=\beta_{o}+\beta_{1} \text { ENDlp }_{i}+\beta_{2} \text { CRESv }_{i}+\beta_{3} \text { TAM } \varepsilon_{i} \\
& \text { PERFORMANCE }_{i}=\beta_{o}+\beta_{1} \text { ENDgl }_{i}+\beta_{2} \text { CRESv }_{i}+\beta_{3} \text { TAM } \varepsilon_{i}
\end{aligned}
$$


QUADRO 1 - Descrição das variáveis do estudo

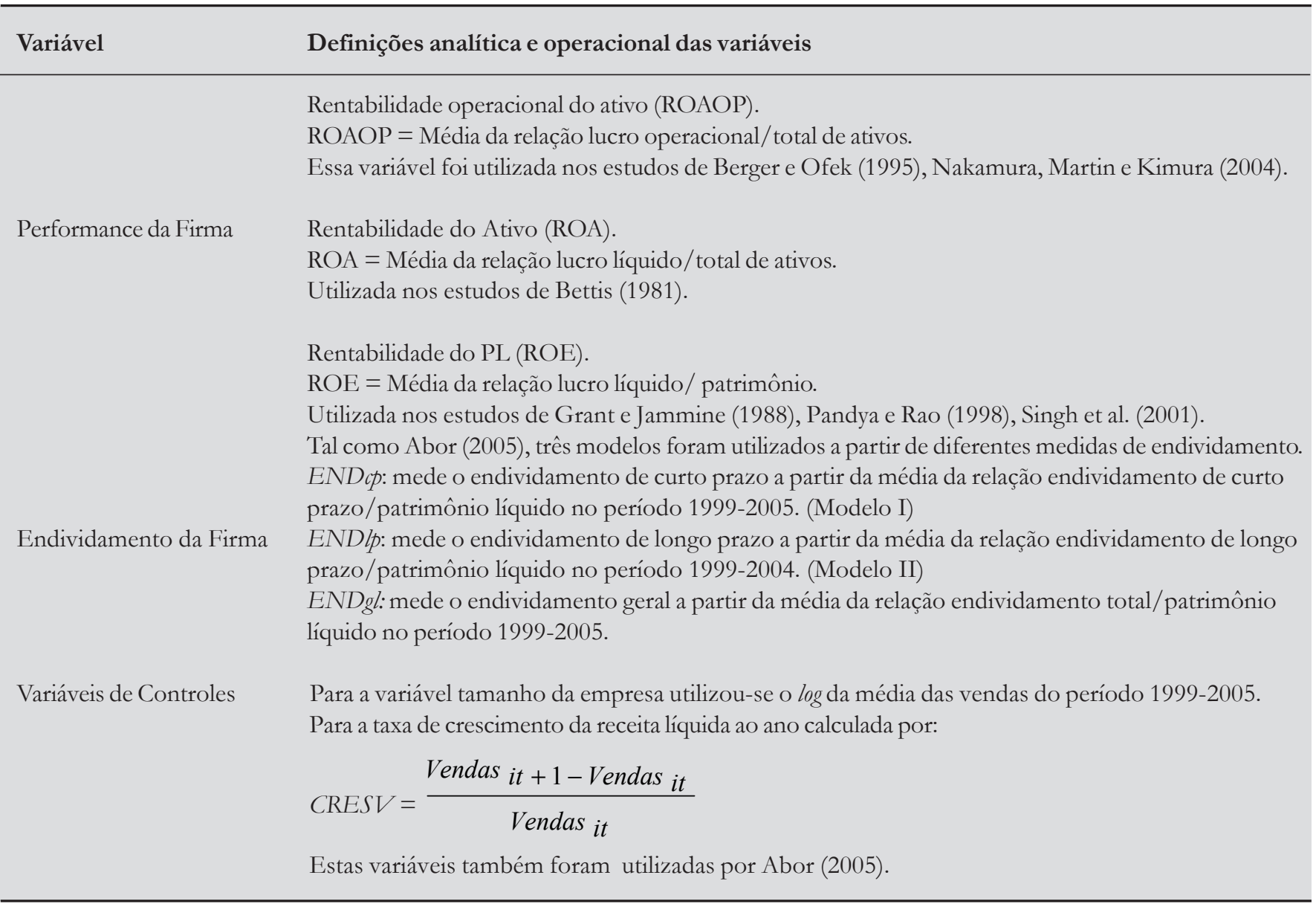

Fonte: Os autores.

Os trabalhos empíricos anteriores, tais como Rajan e Zingales (1995), Jorge e Armada (1999), Nakamura, Martin e Kimura, (2004), sugerem que os credores preferem emprestar para empresas que detenham ativos fixos, pois estes servem de colaterais como garantia em caso de dificuldade financeira.

Considerando que o mercado brasileiro privilegia firmas com estas características e que empresas com maior índice de ativos fixos possuem maior credibilidade e acesso a créditos subsidiados pagando juros menores (BARCELOS, 2002), o pressuposto adotado é que empresas com maior ativo tangível são mais endividadas no longo prazo e, por conseguinte, obtém melhor performance.

\section{ANÁLISE DOS DADOS}

Nesta seção apresentam-se os principais resultados do estudo da estrutura de capital das empresas e sua relação com a performance. A Tabela 1 apresenta as médias das variáveis estudadas. 
TABELA 1 - Médias das rentabilidades, endividamento curto prazo, longo prazo e geral, crescimento das vendas e tamanho da empresa de cada setor

\begin{tabular}{lllllllll}
\hline Setores & ROA $\%$ & ROAOP\% & ROE\% & ENDcp \% & ENClp\% & ENDg1\% & CRESv\% & TAM \$ \\
\hline Comércio (5) & $-0,03$ & 7,69 & $-13,4$ & 50,44 & 87,89 & 138,33 & 1,12 & 2.638 .421 \\
Têxtil (7) & $-0,82$ & 8,05 & $-7,99$ & 57,59 & 63,19 & 120,78 & 1,15 & 443.738 \\
Eletro Eletr. (3) & $-1,96$ & 3,84 & $-7,47$ & 74,05 & 56,42 & 130,47 & 1,12 & 988.556 \\
Telecom. (16) & 0,85 & 6,81 & $-1,64$ & 37,88 & 46,87 & 84,75 & 1,31 & 3.321 .153 \\
Construção (7) & 1,1 & 5,13 & 4,63 & 51,41 & 72,76 & 124,17 & 1,21 & 133.330 \\
Química (13) & 4,04 & 12,87 & 5,02 & 38,86 & 88,83 & 127,69 & 1,32 & 1.820 .797 \\
Outros (16) & 2,17 & 5,94 & 5,37 & 42,14 & 60,31 & 102,45 & 1,13 & 694.556 \\
Ener Elétrica (21) & 1,15 & 7,47 & 6,85 & 32,48 & 65,79 & 98,26 & 1,20 & 1.817 .314 \\
Al. Bebidas (9) & 2,71 & 9,93 & 7,56 & 46,98 & 82,6 & 129,58 & 1,26 & 3.051 .876 \\
Veíc e peças (8) & 2,58 & 14,32 & 8,75 & 51,18 & 48,89 & 100,07 & 1,24 & 1.333 .679 \\
Sid Metal.(10) & 4,76 & 13,63 & 12,15 & 48,43 & 62,03 & 110,46 & 1,25 & 3.687 .781 \\
Trans Serv (2) & 4,43 & 12,80 & 12,9 & 24,56 & 135,98 & 160,54 & 1,21 & 514.245 \\
Papel Celul (6) & 6,61 & 12,50 & 13,68 & 34,28 & 66,27 & 100,55 & 1,26 & 1.828 .717 \\
Petróleo Gás (4) & 6,29 & 18,63 & 19,62 & 38,28 & 47,07 & 85,35 & 1,30 & 3.555 .793 \\
Mineração (2) & 10,39 & 28,49 & 22,37 & 36,69 & 58,69 & 95,39 & 1,30 & 9.898 .342 \\
Máq. Indus (1) & 12,66 & 18,48 & 29,59 & 68,14 & 18,53 & 86,67 & 1,25 & 1.455 .463 \\
Total empresas & 130 & & & & & & & \\
\hline
\end{tabular}

Fonte: Os autores.

Os resultados apresentados na Tabela 1 remetem aos estudos anteriores, realizados por Titman e Wessels (1988) para o mercado americano, e de Kayo e Famá (1997), Perobelli e Famá (2002) para o Brasil, os quais revelam que empresas menos rentáveis apresentam endividamento maior em relação as mais rentáveis o que não parece caracterizar neste estudo.

A Tabela 2 fornece um resumo da estatística descritiva das variáveis dependentes e independentes da amostra.

TABELA 2 - Descrição das variáveis utilizadas

\begin{tabular}{lllllll}
\hline Variáveis & Média & Desvio Padrão & Mínimo & Máximo & Assimetria & Curtose \\
\hline ROA & 2,47 & 4,868 & $-13,214$ & 13,94 & $-0,540$ & 1,059 \\
ROAOP & 9,70 & 6,630 & $-12,885$ & 33,09 & 0,167 & 1,971 \\
ROE & 5,20 & 17,540 & $-62,117$ & 78,60 & $-0,515$ & 4,224 \\
ENDgl & 42,85 & 17,115 & 9,057 & 98,66 & 0,623 & 0,199 \\
ENDcp & 65,85 & 46,001 & 4,229 & 213,51 & 1,022 & 0,799 \\
ENDlp & 108,70 & 47,812 & 43,500 & 238,79 & 0,867 & 0,120 \\
CRESv & 1,23 & 0,174 & 0,696 & 1,93 & 1,148 & 3,358 \\
TAM & $2.682 .867,47$ & $7.316 .962,018$ & $9.297,429$ & 78.087 .393 & 8,754 & 88,777 \\
\hline
\end{tabular}

Fonte: Os autores. 
Conforme mencionado anteriormente, foram considerados para os indicadores de estrutura todos os passivos operacionais das empresas. $\mathrm{O}$ presente estudo parece alterar o nível do endividamento geral que, de acordo com Nakamura, Martin e Kimura (2004), no período de 1999 a 2003, o percentual de endividamento geral era de $73,43 \%$ contra $42,85 \%$ apresentados neste.

Observa-se, também, que na rentabilidade do patrimônio líquido (ROE) existe grande dispersão devido ao seu alto desvio padrão e, de acordo com a assimetria, esta se apresenta de forma assimétrica negativa, demonstrando que um número expressivo de empresas operam com rentabilidade negativa. Alta dispersão também é percebida nas vendas representada pela variável TAM, todavia, de forma contrária a ROE, visto que sua assimetria é positiva, indicando que maior número de empresas efetuam grandes montantes de vendas. O mesmo é observado na variável endividamento geral (ENDgl).

A Tabela 3 apresenta os resultados das correlações e respectivas significâncias para todas as variáveis consideradas na pesquisa.

TABELA 3 - Matriz de correlação das variáveis dos modelos

\begin{tabular}{lllllllll}
\hline Variáveis & ROA & ROAOP & ROE & CRESv & ENDcp & ENDlp & ENDg & ITAM \\
\hline ROA & 1 & & & & & & & \\
ROAOP & $0,74^{*}$ & 1 & & & & & & \\
ROE & $0,81^{*}$ & $0,60^{*}$ & 1 & & & & \\
CRESv & 0,14 & $0,24^{*}$ & 0,13 & 1 & & & \\
ENDcp & $-0,29$ & $-0,18^{\text {a }}$ & $-0,22^{\text {a }}$ & $-0,14^{\mathrm{b}}$ & 1 & & \\
ENDlp & $-0,07$ & $-0,07$ & $-0,10$ & 0,05 & $-0,10$ & 1 & \\
ENDgl & $-0,19^{\text {a }}$ & $-0,14^{\mathrm{b}}$ & $-0,18^{\text {a }}$ & $-0,00$ & $0,30^{*}$ & $0,90^{*}$ & 1 & \\
TAM & $0,35^{*}$ & $0,48^{*}$ & $0,29^{*}$ & $0,31^{*}$ & $-0,28^{*}$ & $-0,06$ & $-0,17^{\text {a }}$ & 1 \\
\hline
\end{tabular}

Fonte: Os autores.

* significativo a $1 \%{ }^{\text {a }}$ significativo a $5 \%$; ${ }^{\text {b }}$ significativo a $10 \%$.

As variáveis CRESv e TAM embora tenham apresentado alta correlação, no entanto foi feito o teste stepwise, o qual sugeriu a inclusão das duas variáveis, visto que, com a exclusão de uma dessas o poder explicativo $\left(\mathbf{R}_{\text {ajustado }}^{2}\right)$ dos modelos de regressão ficaria reduzido. Por sua vez, a alta correlação entre as variáveis de endividamento não foi levado em conta, tendo em vista que somente uma destas foi acrescentada em cada modelo de regressão apresentados na Tabela 4 . 
TABELA 4 - Coeficientes estimados para amostra com os três modelos

\begin{tabular}{|c|c|c|c|c|c|c|c|c|c|}
\hline \multirow[b]{2}{*}{$\begin{array}{l}\text { V.Dep } \\
\text { V. Ind. }\end{array}$} & \multicolumn{3}{|c|}{$\begin{array}{l}\text { Modelo I Endividamento de } \\
\text { curto prazo: ENDcp }\end{array}$} & \multicolumn{3}{|c|}{$\begin{array}{l}\text { Modelo II Endividamento de } \\
\text { longo prazo: ENDlp }\end{array}$} & \multicolumn{3}{|c|}{$\begin{array}{l}\text { Modelo III Endividamento } \\
\text { geral: ENDgl }\end{array}$} \\
\hline & ROA & ROAOP & ROE & ROA & ROAOP & ROE & ROA & ROAOP & ROE \\
\hline Constante & $\begin{array}{l}-4,858 \\
(0,319)\end{array}$ & $\begin{array}{l}-17,877 \\
(0,005)^{*}\end{array}$ & $\begin{array}{l}-22,144 \\
(0,224)\end{array}$ & $\begin{array}{l}-11,775^{*} \\
(0,004)\end{array}$ & $\begin{array}{l}-18,989 * \\
(0,000)\end{array}$ & $\begin{array}{l}-37,048 \\
{ }^{\mathrm{a}}(0,013)\end{array}$ & $\begin{array}{l}-4,658 \\
(0,450)\end{array}$ & $\begin{array}{l}-14,236^{\mathrm{b}} \\
(0,071)\end{array}$ & $\begin{array}{l}-11,979 \\
(0,597)\end{array}$ \\
\hline CRESv & $\begin{array}{l}0,633 \\
(0,792)\end{array}$ & $\begin{array}{l}3,944 \\
(0,207)\end{array}$ & $\begin{array}{l}3,773 \\
(0,674)\end{array}$ & $\begin{array}{l}1,164 \\
(0,637)\end{array}$ & $\begin{array}{l}4,212 \\
(0,178)\end{array}$ & $\begin{array}{l}5,507 \\
(0,543)\end{array}$ & $\begin{array}{l}1,214 \\
(0,618)\end{array}$ & $\begin{array}{l}4,183 \\
(0,179)\end{array}$ & $\begin{array}{l}5,449 \\
(0,543)\end{array}$ \\
\hline TAM & $\begin{array}{l}0,850^{*} \\
(0,001)\end{array}$ & $\begin{array}{l}1,766^{*} \\
(0,000)\end{array}$ & $\begin{array}{l}2,586^{*} \\
(0,008)\end{array}$ & $\begin{array}{l}0,995^{*} \\
(0,000)\end{array}$ & $\begin{array}{l}1,790^{*} \\
(0,000)\end{array}$ & $\begin{array}{l}2,901^{*} \\
(0,002)\end{array}$ & $\begin{array}{l}0,935^{*} \\
(0,000)\end{array}$ & $\begin{array}{l}1,754^{*} \\
(0,000)\end{array}$ & $\begin{array}{l}1,754^{*} \\
(0,005)\end{array}$ \\
\hline ENDcp & $\begin{array}{l}-0,785^{a} \\
(0,013)\end{array}$ & $\begin{array}{l}-0,206 \\
(0,613)\end{array}$ & $\begin{array}{l}-1,950^{\mathrm{b}} \\
(0,099)\end{array}$ & na & na & na & na & na & na \\
\hline ENDlp & & na & na & $\begin{array}{l}-0,097 \\
(0,497)\end{array}$ & $\begin{array}{l}-0,114 \\
(0,528)\end{array}$ & $\begin{array}{l}-0,529 \\
(0,315)\end{array}$ & na & na & na \\
\hline ENDgl & & na & na & na & na & na & $\begin{array}{l}-3,557 \\
(0,104)\end{array}$ & $\begin{array}{l}-2,553 \\
(0,358)\end{array}$ & $\begin{array}{l}-13,198 \\
(0,101)\end{array}$ \\
\hline$F$ & $\begin{array}{l}8,632 * \\
(0,000)\end{array}$ & $\begin{array}{l}14,047^{*} \\
(0,000)\end{array}$ & $\begin{array}{l}5,233^{*} \\
(0,001)\end{array}$ & $\begin{array}{l}6,427 * \\
(0,000)\end{array}$ & $\begin{array}{l}14,111 \\
(0,000)\end{array}$ & $\begin{array}{l}4,593^{*} \\
(0,004)\end{array}$ & $\begin{array}{l}7,275^{*} \\
(0,000)\end{array}$ & $\begin{array}{l}14,311^{*} \\
(0,000)\end{array}$ & $\begin{array}{l}5,21)^{*} \\
(0,001)\end{array}$ \\
\hline $\mathrm{R}_{\text {ajustado }}^{2}$ & $15,07 \%$ & $23,27 \%$ & $8,96 \%$ & $11,20 \%$ & $23,36 \%$ & $7,71 \%$ & $12,73 \%$ & $23,63 \%$ & $8,93 \%$ \\
\hline
\end{tabular}

Fonte: Os autores.

* significativo a $1 \%{ }^{\text {a }}$ significativo a $5 \%$; ${ }^{\text {b }}$ significativo a $10 \%$.

$\mathrm{Na}$ análise de regressão usada para verificar a relação entre estrutura de capital e a performance o resultado para o modelo I denota que as variáveis dependentes ROA, ROAOP e ROE foram explicadas respectivamente em 15,07\%, 23,27\% e $8,96 \%$ pelo conjunto de variáveis independentes. $\mathrm{O}$ teste $\mathrm{F}$ também se apresentou significativo em todas as variáveis, o que indica que o quociente angular $\mathrm{R}^{2}$ é maior que zero, apresentando um bom ajustamento. Já os coeficientes ( $p$ ) não apresentaram forte significância estatística na variável endividamento de curto prazo, no entanto, influenciando negativamente em todas as variáveis de performance, caracterizando os pressupostos de Barcelos (2002) os quais apontam que empresas com maior índice de endividamento no curto prazo pagam taxas de juros mais elevadas. Isto sugere que empresas com endividamento no curto prazo tendem a ser menos rentáveis e, portanto, aceita-se a hipótese H1. Este resultado diverge dos encontrados por Mesquita e Lara (2003) e Abor (2005), em que esse índice se mostrou significativamente positivo.

Para o modelo II, a variável endividamento de longo prazo (ENDlp) não apresentou significância estatística e, portanto, a $\mathrm{H} 2$ for rejeitada. Todavia seus resultados foram negativos em todas as variáveis de performance e este seguiu a mesma tendência explicativa do modelo I em que a variável de performance ROAOP obteve maior índice de explicação $(23,36 \%)$.

Resultado semelhante pode ser visto no modelo III da regressão, no entanto, a variável endividamento geral (ENDgl), embora não significativa, apresentou resultado negativo em todas as variáveis de performance e também não confirmando a hipótese H3. 
Observa-se, portanto, que o tamanho das vendas influencia estatisticamente e positivamente na performance das empresas, corroborando com a pesquisas de Abor (2005), em que esta se manteve significativa em todos os modelos de regressão.

Destaca-se que foram feitos testes com a variável idade das empresas e com a indústria e estas não apresentaram significância estatística em nenhum dos modelos.

A Tabela 5, a seguir, apresenta os três modelos de regressão com as variáveis ENDcp, ENDlp e ENDgl dos setores com dez ou mais empresas por setor.

TABELA 5 - Coeficientes estimados para a amostra dos setores tendo como variável dependente o ROA

\begin{tabular}{|c|c|c|c|c|c|c|c|c|}
\hline \multirow{2}{*}{$\begin{array}{l}\text { Setor. } \\
\text { (N.empres) }\end{array}$} & \multicolumn{7}{|c|}{ Variável dependente ROA } & \multirow[b]{2}{*}{$\mathbf{R}_{\text {ajustado }}^{2}$} \\
\hline & Constante & ENDcp & ENDlp & ENDg1 & CRESv & TAM & $\mathbf{F}$ & \\
\hline & $\begin{array}{l}-23,965^{\mathrm{b}} \\
(0,051)\end{array}$ & $\begin{array}{l}-0,022 \\
(0,972)\end{array}$ & na & na & $\begin{array}{l}6,115 \\
(0,360)\end{array}$ & $\begin{array}{l}1,285^{a} \\
(0,041)\end{array}$ & $\begin{array}{l}1,931 \\
(0,162)\end{array}$ & $12,26 \%$ \\
\hline \multirow[t]{3}{*}{ E. Elétrica (21) } & $\begin{array}{l}-26,841^{a} \\
(0,026)\end{array}$ & na & $\begin{array}{l}-0,309 \\
(0,242)\end{array}$ & na & $\begin{array}{l}7,614 \\
(0,229)\end{array}$ & $\begin{array}{l}1,522^{\mathrm{a}} \\
(0,019)\end{array}$ & $\begin{array}{l}2,587 \\
(0,086)\end{array}$ & $19,23 \%$ \\
\hline & $\begin{array}{l}-20,366^{\mathrm{b}} \\
(0,084)\end{array}$ & na & na & $\begin{array}{l}-4,316 \\
(0,228)\end{array}$ & $\begin{array}{l}8,040 \\
(0,209)\end{array}$ & $\begin{array}{l}1,455 \\
\mathrm{a}(0,020)\end{array}$ & $\begin{array}{l}2,628^{\mathrm{b}} \\
(0,083)\end{array}$ & $19,63 \%$ \\
\hline & $\begin{array}{l}6,178 \\
(0,837)\end{array}$ & $\begin{array}{l}-2,634^{\mathrm{b}} \\
(0,094)\end{array}$ & na & na & $\begin{array}{l}-15,239^{\mathrm{b}} \\
(0,095)\end{array}$ & $\begin{array}{l}2,433 \\
(0,186)\end{array}$ & $\begin{array}{l}2,393 \\
(0,135)\end{array}$ & $25,83 \%$ \\
\hline \multirow[t]{3}{*}{ Química (13) } & $\begin{array}{l}-31,829 \\
(0,172)\end{array}$ & na & $\begin{array}{l}-0,750^{\mathrm{b}} \\
(0,097)\end{array}$ & na & $\begin{array}{l}-4,416 \\
(0,546)\end{array}$ & $\begin{array}{l}3,442^{\mathrm{b}} \\
(0,069)\end{array}$ & $\begin{array}{l}2,368 \\
(0,138)\end{array}$ & $25,48 \%$ \\
\hline & $\begin{array}{l}-10,563 \\
(0,648)\end{array}$ & na & na & $\begin{array}{l}-11,774^{\mathrm{b}} \\
(0,057)\end{array}$ & $\begin{array}{l}-5,766 \\
(0,404)\end{array}$ & $\begin{array}{l}3,304^{b} \\
(0,066)\end{array}$ & $\begin{array}{l}2,942^{\mathrm{b}} \\
(0,091)\end{array}$ & $32,68 \%$ \\
\hline & $\begin{array}{l}-11,553 \\
(0,633)\end{array}$ & $\begin{array}{l}-0,458 \\
(0,772)\end{array}$ & na & na & $\begin{array}{l}7,025 \\
(0,541)\end{array}$ & $\begin{array}{l}0,743 \\
(0,534)\end{array}$ & $\begin{array}{l}2,855 \\
(0,126)\end{array}$ & $38,21 \%$ \\
\hline \multirow[t]{3}{*}{ Sid. Met. (10) } & $\begin{array}{l}-18,953 \\
(0,148)\end{array}$ & na & $\begin{array}{l}0,090 \\
(0,739)\end{array}$ & na & $\begin{array}{l}7,828 \\
(0,524)\end{array}$ & $\begin{array}{l}0,923 \\
(0,181)\end{array}$ & $\begin{array}{l}2,879 \\
(0,125)\end{array}$ & $35,52 \%$ \\
\hline & $\begin{array}{l}-19,971 \\
(0,260)\end{array}$ & na & na & $\begin{array}{l}0,799 \\
(0,853)\end{array}$ & $\begin{array}{l}6,804 \\
(0,568)\end{array}$ & $\begin{array}{l}1,016 \\
(0,101)\end{array}$ & $\begin{array}{l}2,815 \\
(0,130)\end{array}$ & $36,65 \%$ \\
\hline & $\begin{array}{l}32,500 \\
(0,158)\end{array}$ & $\begin{array}{r}-4,363^{\mathrm{a}} \\
(0,039)\end{array}$ & na & na & $\begin{array}{l}2,243 \\
(0,726)\end{array}$ & $\begin{array}{l}-0,554 \\
(0,597)\end{array}$ & $\begin{array}{l}1,790 \\
(0,202)\end{array}$ & $13,64 \%$ \\
\hline \multirow[t]{3}{*}{ Teles (16) } & $\begin{array}{l}20,085 \\
(0,344)\end{array}$ & na & $\begin{array}{l}-1,207^{\mathrm{b}} \\
(0,086)\end{array}$ & na & $\begin{array}{l}-1,379 \\
(0,836)\end{array}$ & $\begin{array}{l}-0,673 \\
(0,560)\end{array}$ & $\begin{array}{l}1,175 \\
(0,359)\end{array}$ & $3,39 \%$ \\
\hline & $\begin{array}{l}65,492^{a} \\
(0,040)\end{array}$ & na & na & $\begin{array}{l}-24,138^{*} \\
(0,018)\end{array}$ & $\begin{array}{l}-0,872 \\
(0,883)\end{array}$ & $\begin{array}{l}-1,232 \\
(0,262)\end{array}$ & $\begin{array}{l}2,530 \\
(0,106)\end{array}$ & $23,43 \%$ \\
\hline & $\begin{array}{l}21,745 \\
(0,123)\end{array}$ & $\begin{array}{l}-1,669^{a} \\
(0,039)\end{array}$ & na & na & $\begin{array}{l}-6,211 \\
(0,539)\end{array}$ & $\begin{array}{l}-0,174 \\
(0,802)\end{array}$ & $\begin{array}{l}2,116 \\
(0,151)\end{array}$ & 18,25 \\
\hline \multirow[t]{2}{*}{ Outros (16) } & $\begin{array}{l}11,910 \\
(0,530)\end{array}$ & na & $\begin{array}{l}-0,089 \\
(0,875)\end{array}$ & na & $\begin{array}{l}-10,169 \\
(0,430)\end{array}$ & $\begin{array}{l}0,193 \\
(0,816)\end{array}$ & $\begin{array}{l}0,231 \\
(0,872)\end{array}$ & $5,46 \%$ \\
\hline & $\begin{array}{l}41,068 \\
(0,157)\end{array}$ & na & na & $\begin{array}{l}-10,917 \\
(0,213)\end{array}$ & $\begin{array}{l}-13,190 \\
(0,266)\end{array}$ & $\begin{array}{l}-0,204 \\
(0,804)\end{array}$ & $\begin{array}{l}0,832 \\
(0,501)\end{array}$ & $3,47 \%$ \\
\hline \multirow[t]{3}{*}{ Outros $^{1}(54)$} & $\begin{array}{l}-11,126 \\
(0,148)\end{array}$ & $\begin{array}{l}-1,004^{\mathrm{b}} \\
(0,059)\end{array}$ & na & na & $\begin{array}{l}1,862^{\mathrm{b}} \\
(0,600)\end{array}$ & $\begin{array}{l}1,372^{*} \\
(0,000)\end{array}$ & $\begin{array}{l}9,755^{*} \\
(0,000)\end{array}$ & $33,13 \%$ \\
\hline & $\begin{array}{l}-22,163^{*} \\
(0,000)\end{array}$ & na & $\begin{array}{l}0,032 \\
(0,890)\end{array}$ & na & $\begin{array}{l}3,454 \\
(0,343)\end{array}$ & $\begin{array}{l}1,518^{*} \\
(0,000)\end{array}$ & $(7,925)$ & $28,16 \%$ \\
\hline & $\begin{array}{l}-15,817 \\
(0,127)\end{array}$ & na & na & $\begin{array}{l}-2,606 \\
(0,490)\end{array}$ & $\begin{array}{l}3,672 \\
(0,304)\end{array}$ & $\begin{array}{l}1,439 * \\
(0,000)\end{array}$ & $\begin{array}{l}8,154^{*} \\
(0,000)\end{array}$ & $28,82 \%$ \\
\hline
\end{tabular}


Neste modelo (Tabela 5), identifica-se que a variável endividamento de curto prazo (ENDcp) apresentou significância estatística entre $5 \%$ e 10\% em quase todos os setores, exceto Energia Elétrica e Siderúrgica e Metalúrgica. Todavia, tiveram resultado negativo, indicando que o endividamento influencia negativamente na performance medida pelo ROA. Por outro lado, no endividamento de longo prazo (ENDlp) somente os setores Química e Telecomunicação foram significativamente negativas, enquanto os setores Siderúrgica e Metalúrgica e Outros ${ }^{1}$ embora não significativos, tiveram seus resultados positivos. O mesmo comportamento é observado na variável endividamento geral (ENDgl), em que somente os setores Química e Teles foram significativamente negativas.

Por sua vez, a exemplo dos três modelos (Tabela 5), a variável crescimento das vendas (CRESv) não apresentou significância estatística em nenhum dos setores estudados. Já o tamanho das vendas (TAM) apresentou significância estatística de 5\% para os setores Energia Elétrica em todos os modelos, de acordo com as variáveis de endividamento ENDcp, ENDlp e ENDgl, e o setor Outros $^{1}$ foi significativo em 1\% também em todos o modelos de regressão. Para o setor Química a variável TAM apresentou significância estatística a nível de 10\% nos modelos ENDlp e ENDgl, enquanto para os demais setores o tamanho das vendas não foi significativo em nenhum modelo. Outra observação é feita nos setores Teles e Outros, em que, para o primeiro, no modelo ENDlp, a explicação foi de apenas 3,39\% pelas variáveis e para o setor Outros, nos modelos ENDcp e ENDlp, foram respectivamente de $5,46 \%$ e $3,47 \%$.

\section{CONCLUSÕES}

O presente estudo teve como objetivo avaliar a influência da estrutura de capital na performance. Os resultados apontaram que somente o endividamento de curto prazo influenciou estatisticamente e negativamente na performance medida pelas variáveis ROE e ROA, corroborando, portanto, com a afirmação de Barcelos (2002), o qual aponta que empresas com maior índice de endividamento no curto prazo pagam taxas de juros mais elevadas e, com isso, sofrem perdas em sua rentabilidade. Todavia, para as demais variáveis de endividamento, embora não apresentando significância estatística, estas mostraram resultados negativos contrariando, portanto, a teoria de Modigliani e Miller (1958) sobre a irrelevância da estrutura de capital.

Algumas limitações do estudo merecem destaque, em especial, por servirem de subsídio ao aprofundamento desta pesquisa. Face ao número de parâmetros estimados na regressão, o reduzido número de empresas em algumas das regressões individualizadas por indústria faz com que os resultados devam ser analisados com cautela.

Considerando a complexidade do assunto estrutura de capital e a também complexa e controversa relação com o desempenho das empresas, este estudo, como outros, não esgota o assunto. Porém, espera-se que contribua para novas reflexões quanto à necessidade de trabalhos empíricos que levem ao melhor entendimento destas variáveis, em especial, em economias emergentes e ambientes turbulentos como o Brasil.

\section{REFERÊNCIAS}

ABOR, J. The effect of capital structure on profitability: an empirical analysis of listed firms in Ghana. The Journal of Risk Finance, v. 5, n. 5, p. 438, 2005.

ABRAS, M. A. et al. Finanças corporativas e estratégia empresarial: alavancagem financeira, turbulência do ambiente e performances empresariais. In: ENCONTRO ANUAL DA ASSOCIAÇÃO NACIONAL DE PÓS-GRADUAÇÃO E PESQUISA EM ADMINISTRAÇÃO, 27., 2003, Atibaia. Anais... Atibaia: EnANPAD, 2003. p. 1-16.

ANDERSEN, T. J. Risk management, capital structure, and performance: a real options perspective. Global Business \& Economics Anthology, v. 24, n. 2, p. 1-19, Sept. 2005.

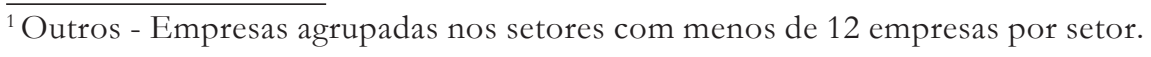


BALAKRISHNAN, S.; FOX, I. Asset specificity, firm heterogeneity and capital structure. Strategic Management Journal, v. 14, p. 3-16, 1993.

BANCEL, F.; MITOO, U. R. Cross-country determinantes of capital structure choice: a survey of european firms. Financial Management, v. 59, n. 1, p. 103-132, 2004.

BANDEIRA-DE-MELLO, R.; MARCON, R. A mensuração multivariada da performance e suas componentes de variância: uma análise do efeitos do ano, indústria e firma no contexto brasileiro. In: ENCONTRO ANUAL DA ASSOCIAÇÃO NACIONAL DE PÓS-GRADUAÇÃO E PESQUISA EM ADMINISTRAÇÃ̆O, 28., 2004, Curitiba. Anais... Curitiba: EnANPAD, 2004. p. 1-16.

BARCELOS, L. C. Teoria e evidências empiricas: determinantes do acesso ao crédito empresarial no Brasil. 2002. 84 f. Dissertação (Mestrado em Economia) - Faculdade de Economia, Administração e Contabilidade, Universidade de São Paulo, São Paulo, 2002.

BARTON, S. L.; GORDON, P. J. Corporate strategy and capital structure. Strategic Management Journal, v. 9, n. 6, p. 623-632, Nov./Dec. 1988.

BASKIN, J. An empirical investigation of the pecking order hypothesis. Financial Management, v. 18, n. 1, p. 26, 1989.

BASTOS, R. R.; HIDALGO, A. de M. Determinantes do endividamento das empresas brasileiras. In: ENCONTRO NORTE NORDESTE DE FINANÇAS, 2., 2005, Recife. Anais... Recife: Encontro de Finanças, 2005. p. 1-16.

BAXTER, N. D. Leverage, risk of ruin and the cost of capital. American Finance Association, Sept. 1967.

BRITO, R. D.; LIMA, M. R. A escolha da estrutura de capital sob fraca garantia legal. Revista Brasileira de Economia, v. 59, n. 2, p. 177-208, 2005.
DEANGELO, H.; MASULIS, R. W. Optimal capial structure under corporate and personal taxation. Journal of Financial Economics, v. 8, p. 3-29, 1980.

EID Jr., W. Custo e estrutura de capital: o comportamento das empresas brasileiras. Caderno de Pesquisas em Administração, v. 36, n. 4, p. 51-59, out./dez. 1996.

FAMA, R.; BARROS, L. A. B. de C.; SILVEIRA, A. D. M. da. A estrutura de capital é relevante? Novas evidências a partir de dados norte-americanos e latino-americanos. Caderno de Pesquisas em Administração, v. 8, n. 2, abr./jun. 2001.

FAMA, R.; MELHER, S. A estrutura de capital na América Latina: existiria uma correlação com o lucro das empresas? In: SEMEAD SEMINÁRIO EM ADMINISTRAÇÃO, 4., 1999, São Paulo. Anais... São Paulo: FEA/USP, 1999. p. 1-16.

HAIR, J. et al. Multivariate data analysis. $5^{\text {th }}$ ed. New Jersey: Prentice Hall, 1995.

HEINKEL, R.; ZECHNER, J. The role of debt and preferred stock as a solution to adverse investment incentives. Journal of Financial and Quantitative Analysis, v. 25, n. 1, p. 1, Mar. 1990.

JENSEN, M. C.; MECKLING, W. H. Theory of the firm: managerial behavior, agency costs and ownership structure. Journal of Financial Economics, v. 3, p. 305-360, 1976.

JORGE, S.; ARMADA. M. J. R. Factores determinantes do endividamento: uma análise em painel. Revista de Administração Contemporânea, v. 5, n. 2, p. 9-31, maio/ago. 2001.

KAYO, E. K.; FAMÁ, R. Teoria de agência e crescimento: evidências empíricas dos efeitos positivos e negativos do endividamento. Caderno de Pesquisas em Administração, v. 2, n. 5, p. 1-8, 1997.

KOCHHAR, R. Strategic assets, capital structure, and firm performance. Journal of Financial and Strategic Decisions, v. 10, n. 3, p. 23-36, 1997. 
LUCINDA, C. R. de; SAITO, R. Determinantes do endividamento das empresas brasileiras volume e composição. Ibmec Business Scholl. In: ENCONTRO BRASILEIRO DE ECONOMETRIA, 2002, Nova Friburgo. Anais... Nova Friburgo: EBE, 2002. p. 1-16.

MEDEIROS, O. R. de; DAHER C. E. Testes empíricos da Pecking Order Theory na estrutura de capital das empresas brasileiras. In: ENCONTRO ANUAL DA ASSOCIAÇÃO NACIONAL DE PÓS-GRADUAÇÃO E PESQUISA EM ADMINISTRAÇÃO, 28., 2004, Curitiba. Anais... Curitiba: EnANPAD, 2004. p. 1-16.

MESQUITA, J. M. C. de; LARA, J. E. Capital structure and profitability: the brazilian case. In: ACADEMY OF BUSINESS AND ADMINISTRATION SCIENCES INTERNATIONAL CONFERENCE, 2003, Vancouver. Proceedings... Vancouver: Directions en Business \& Administrative, 2003. p. 1-14.

MODIGLIANI, F.; MILLER, M. H. Corporate income taxes and the cost of capital: a correction, American Economic Review, v. 53, n. 3, p. 433-443, 1963.

MODIGLIANI, F.; MILLER, M. H. The cost of capital, corporation finance and the theory of investment. American Economic Review, v. 48, n. 3, p. 261-297, June 1958.

MYERS, S. C.; MAJLUF, N. S. Corporate financing and investment decisions when firms have information that investors do not have. Journal of Financial Economics, n. 13, p. 187-221, 1984.

MYERS, S. C. The capital structure puzzle. Journal of Finance, v. 39, n. 3, p. 575-592, July 1984.

NAKAMURA, W. T.; MARTIN, D. M. L.; KIMURA, H. Indicadores contábeis como determinantes do endividamento das empresas brasileiras. In: ENCONTRO ANUAL DA ASSOCIAÇÃO NACIONAL DE PÓS-GRADUAÇÃO E PESQUISA EM ADMINISTRAÇÃO, 28., 2004, Curitiba. Anais... Curitiba: EnANPAD, 2004. p. 1-16.
NARAYANAN, M. P. Debt versus equity under asymmetric information. Journal of Financial and Quantitative Analysis, v. 23, n. 1, p. 39, Mar. 1988.

OLIVEIRA, L. de; ANTONIALLI, L. M. O uso da estrutura de capital por empresas agroindustriais. Organizações Rurais e Agroindustriais, v. 6, n. 2, jul./dez. 2004.

PEREIRA, S. B. C. Análise da relação entre valor e alavancagem no mercado brasileiro. In: ENCONTRO ANUAL DA ASSOCIAÇÃO NACIONAL DE PÓS-GRADUAÇÃO E PESQUISA EM ADMINISTRAÇÃO, 24., 2000, Florianópolis. Anais... Florianópolis: EnANPAD, 2000. p. 1-16.

PEROBELLI, F. F. C.; FAMÁ, R. Determinantes da estrutura de capital: aplicação a empresas de capital aberto brasileiras. Revista de Administração, v. 37, n. 3, p. 3346 jul./set. 2002.

PEROBELLI, F. F. C.; FAMÁ, R. Fatores determinantes da estrutura de capital para empresas Latino-Americanas. Revista de Administração Contemporânea, v. 7, n. 1, p. 935, jan./mar. 2003.

PRATES, C. P. T.; LEAL, R. P. C. Algumas considerações sobre os determinantes da estrutura de capital nas empresas brasileiras. Revista do BNDES, v. 12, n. 2/3, p. 201-218, jun. 2005.

PROCIANOY, J. L.; SCHNORRENBERGER, A. A influência da estrutura de controle nas decisões de estrutura de capital das companhias brasileiras. Revista Brasileira de Economia, v. 58, n. 1, p. 122-146, jan./mar. 2004.

RAJAN, R. G.; ZINGALES, L. What do we know about capital structure? Some evidence from international data. The Journal of Finance, v. 50, n. 5, p. 1421-1460, Dec. 1995.

ROSS, S. A. The determination of financial structure: the incentive-signalling approach. Bell Journal of Economics, v. 8, p. 23-40, 1977. 
SKELY, W. S.; COLLINS, J. M. Cultural influences on international capital structure. Journal of International Business Studies, v. 19, n. 1, p. 87-100, 1988.

SIMERLY, R. L.; LI, M. Environmental dynamism, capital structure and performance: a theoretical integration and an empirical test. Strategic Management Journal, v. 21, p. 3149, 2000.

TITMAN, S.; WESSELS, R. The determinants of capital structure choice. The Journal of Finance, v. 43, n. 1, Mar. 1988.

Recebido: 25/08/2007

Received: 08/25/2007

Aprovado: 21/09/2007

Approved: 09/21/2007 